\title{
Inhibiting Effect of N-Cetyl N,N,N-Trimethyl Ammonium Bromide on Corrosion of Mild Steel in Acidic Medium
}

\author{
Monika, Wequar A. Siddique, Arwind Dubey \\ Department of Applied Sciences \& Humanities, Faculty of Engineering \& Technology \\ Jamia Millia Islamia, New Delhi-110025, India
}

Received 18 December 2004; accepted in revised form 17 September 2005

\begin{abstract}
The inhibiting effect of $\mathrm{N}$-cetyl N,N,N-trimethyl ammonium bromide (CTMAB) on the corrosion of mild steel in $1 \mathrm{~N} \mathrm{H}_{2} \mathrm{SO}_{4}$ solution has been studied by using techniques such as weight loss and electrochemical polarization, infrared (IR) and scanning electron microscopic (SEM) techniques. It is found that $\mathrm{CTMAB}$ is good inhibitor for corrosion of mild steel in $1 \mathrm{~N} \mathrm{H}_{2} \mathrm{SO}_{4}$. The maximum efficiency is about $96 \%$ for CTMAB at $10^{-1} \mathrm{M}$ concentration. The polarization curves indicate that the compound is mixed type inhibitor. The adsorption of inhibitor on mild steel surface is found to obey Langmuir adsorption isotherm. The activation energy $E_{a}$ in the absence and presence of inhibitor is obtained by measuring the temperature dependence of corrosion method. The mechanisms of adsorption of CTMAB on mild steel have been investigated by IR spectra and SEM.
\end{abstract}

Keywords: corrosion, inhibition, N-cetyl N,N,N-trimethyl ammonium bromide (CTMAB), $\mathrm{H}_{2} \mathrm{SO}_{4}$.

\section{Introduction}

Acid solutions are generally used of removal of undesirable scale and rust in several industrial processes. For reducing the corrosion rate of metallic materials in these acidic media, corrosion inhibitors are used. Various types of organic compounds are widely used as corrosion inhibitors. Most organic inhibitors are compound containing nitrogen, phosphor, sulphur and $\mathrm{OH}$ group. By which the molecule can become strongly adsorbed on metal surface.

Most organic inhibitors are compound containing nitrogen, phosphor, sulphur and $\mathrm{OH}$ group. By which the molecule can become strongly adsorbed on metal surface. Corrosion inhibition of nitrogen containing compound have been studied by many authors [1-9]. Most of the authors have tried quaternary ammonium

\footnotetext{
*Corresponding author. E-mail address: jmi_bansal24@yahoo.com
} 
compounds as inhibitors [10-12]. It has also reported that with increase in alkyl chain length increases the effectiveness of inhibitor in alkyl quaternary ammonium compound. The aim of this paper is to study the inhibiting action of $\mathrm{N}$-cetyl N,N,N-trimethyl ammonium bromide (CTMAB) in acidic solution by using weight loss, galvanostatic polarization, FTIR and scanning electron microscopic studies.

\section{Experimental}

The mild steel coupons of composition $(\mathrm{C}=0.20 \%, \mathrm{Mn}=1.00 \%, \mathrm{Si}=0.05 \%$, $\mathrm{S}=0.025 \%, \mathrm{P}=0.25 \%$ and $\mathrm{Fe}=98 \%$ ) and of size (i.e. $0.8 \times 0.8 \times 3.0 \mathrm{~cm}$ ) have been used for weight loss measurements. These coupons are given mechanical polishing and then degreased before use. The inhibition efficiency for different concentrations of inhibitor is calculated from weight loss values.

For polarization studies a cylindrical mild steel rod embedded in araldite is used. The electrodes are polished with emery papers and degreased. AR grade of $\mathrm{H}_{2} \mathrm{SO}_{4}$ acids is used for preparing solutions. Double distilled water is used to prepare all solutions. For accurate measurements of potential and current densities, galvanostatic polarization studies are carried out at different temperatures. A platinum foil and saturated calomel electrode are used as counter and reference electrode, respectively. Polarization is carried out in $\mathrm{H}_{2} \mathrm{SO}_{4}$ in the absence and presence of inhibitor of various concentrations and temperatures.

The Fourier Transform Infrared Spectroscopic analysis (FTIR) spectra of pure inhibitor as well as spectra of inhibitors adsorbed on silica gel are recorded by using Perkin Elmer Infrared Spectroscope IR 137. The pure saturated solutions of additive are prepared in solvent i.e. benzene in which the compound is soluble. Now silica gel, which is dried in an oven to remove the moisture, is added in the additive. The dried solid pallet of the additive mixed in silica gel is used to record the FTIR spectra.

To know the surface morphology of mild steel scanning electron microscopy technique using LEO 435 V.P. Scanning Electron Microscope is used. The polished specimens, which are used in this experiment, are examined to find out any surface defects by optical microscope. From these specimens are taken those which have smooth surface. After this the specimen is washed with double distilled water and dried in desiccators. These specimens are dipped in the solutions of $10^{-1} \mathrm{M}$ and $10^{-7} \mathrm{M}$ concentration for the inhibitor in $1 \mathrm{~N}$ sulphuric acid for 24 hours at room temperature. These specimens are then washed with distilled water and dried in a desiccator. The SEM photographs of these corroded specimens are recorded as well as without corrode mild steel specimen.

\section{Results and discussion}

Weight loss measurements

The inhibition efficiency of CTMAB for corrosion of mild steel is calculated as follows 


$$
\mathrm{I} \%=\frac{W o-W i}{W o} \times 100
$$

where $W_{o}$ and $W i$ are weight losses in the absence and in the presence of inhibitor, respectively.

Table I gives the values of inhibition efficiencies obtained from weight loss studies for various concentrations and temperatures. The inhibition efficiency increases with increasing the concentration of the inhibitor. As the temperature increases, the inhibition efficiency also increases. The inhibition efficiency is maximum about $96 \%$ in case of $\mathrm{H}_{2} \mathrm{SO}_{4}$ acid at the concentration $10^{-1} \mathrm{M}$ for $328 \mathrm{~K}$ temperature.

Table I. Inhibition efficiency of mild steel in the presence of different concentrations of $\mathrm{N}$-cetyl N,N,N-trimethyl ammonium bromide (CTMAB) from weight loss study at various temperatures in $1 \mathrm{~N} \mathrm{H}_{2} \mathrm{SO}_{4}$.

\begin{tabular}{cccc}
\hline $\mathrm{T} / \mathrm{K}$ & Solution $/ \mathrm{mol}\left(\mathrm{L}^{-1}\right)$ & Weight loss $/ \mathrm{g}$ & $\% \mathrm{I}$ \\
\hline 298 & $1 \mathrm{~N} \mathrm{H}_{2} \mathrm{SO}_{4}$ & 0.0786 & - \\
& $10^{-7}$ & 0.0401 & 48.98 \\
& $10^{-5}$ & 0.0241 & 69.33 \\
& $10^{-3}$ & 0.0101 & 87.15 \\
& $10^{-1}$ & 0.0075 & 90.45 \\
\hline 308 & $1 \mathrm{~N} \mathrm{H}_{2} \mathrm{SO}_{4}$ & 0.1568 & - \\
& $10^{-7}$ & 0.0697 & 55.54 \\
& $10^{-5}$ & 0.0618 & 60.58 \\
& $10^{-3}$ & 0.0263 & 83.22 \\
318 & $10^{-1}$ & 0.0088 & 94.38 \\
& $1 \mathrm{~N} \mathrm{H}_{2} \mathrm{SO}_{4}$ & 0.5468 & - \\
& $10^{-7}$ & 0.4439 & 18.81 \\
& $10^{-5}$ & 0.2809 & 48.62 \\
& $10^{-3}$ & 0.0491 & 91.01 \\
& $10^{-1}$ & 0.0258 & 95.28 \\
\hline 328 & $1 \mathrm{~N} \mathrm{H}_{2} \mathrm{SO}_{4}$ & 1.1891 & - \\
& $10^{-7}$ & 0.9313 & 21.68 \\
& $10^{-5}$ & 0.4372 & 63.23 \\
& $10^{-3}$ & 0.1075 & 90.95 \\
& $10^{-1}$ & 0.0475 & 96.00 \\
\hline
\end{tabular}

Polarization measurements

Fig. 1 to 4 show the anodic and cathodic polarization curves of mild steel in $1 \mathrm{~N}$ $\mathrm{H}_{2} \mathrm{SO}_{4}$ solution with and without the addition of various concentration of CTMAB at different temperatures, i.e., $298 \mathrm{~K}, 308 \mathrm{~K}, 318 \mathrm{~K}$ and $328 \mathrm{~K}$. Table II gives the values of various electrochemical parameters: corrosion current density $\left(\mathrm{I}_{\text {corr }}\right), \mathrm{E}_{\text {corr }}, \mathrm{b}_{\mathrm{a}}$ and $\mathrm{b}_{\mathrm{c}}$ for different concentrations. The method used to measure the corrosion current density is the intersection method. 


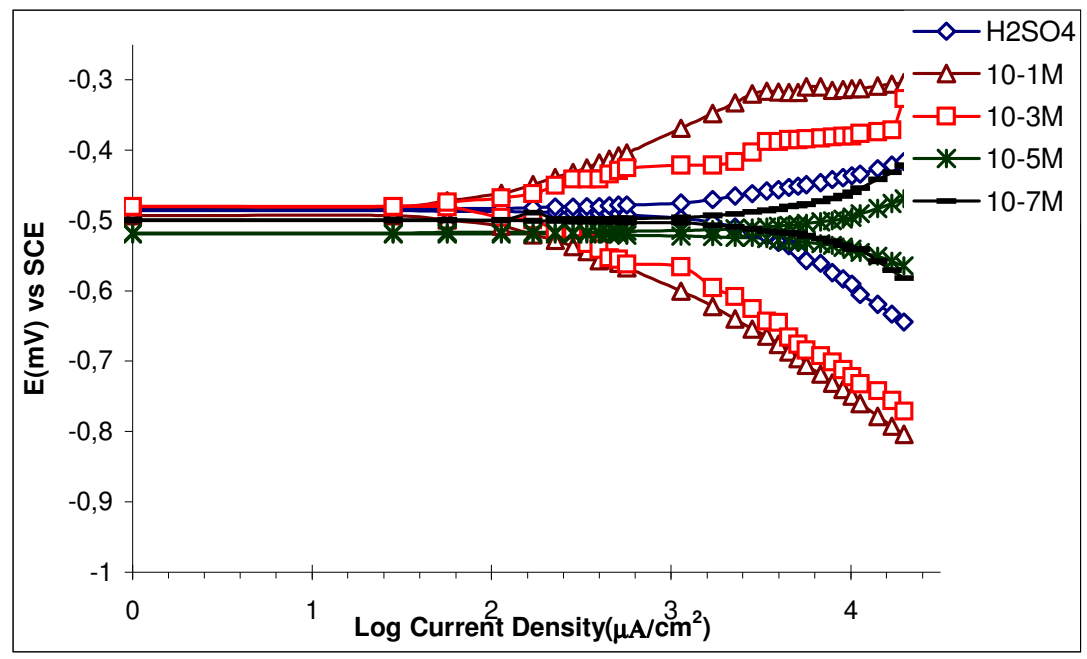

Figure 1. Galvanostatic polarization curves of mild steel in $1 \mathrm{~N}_{2} \mathrm{SO}_{4}$ solution in the presence of different concentrations of CTMAB at $298 \mathrm{~K}$.

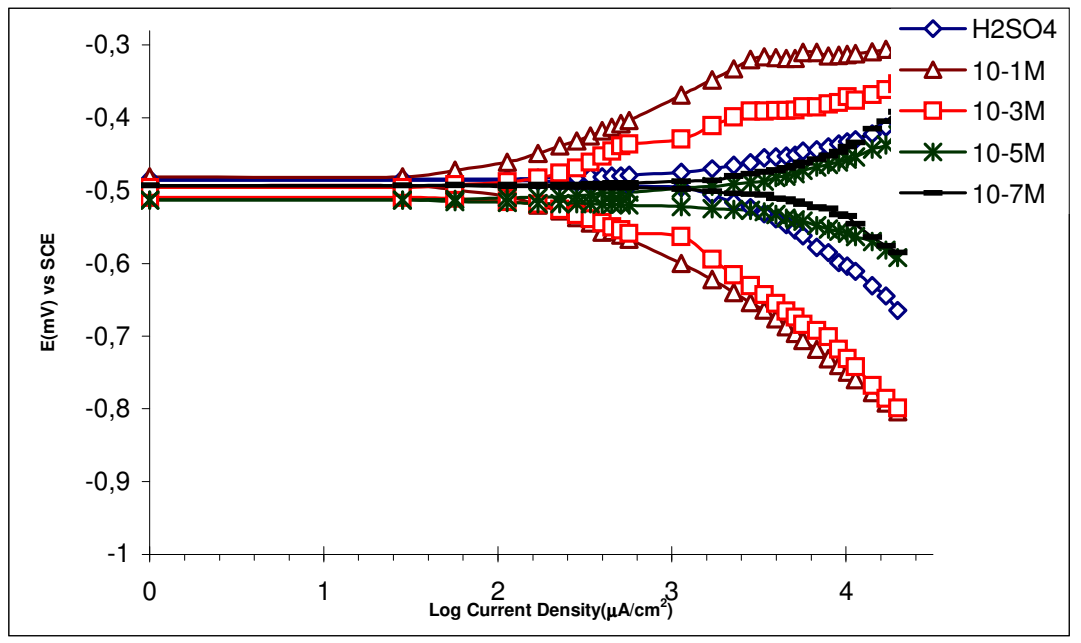

Figure 2. Galvanostatic polarization curves of mild steel in $1 \mathrm{~N}_{2} \mathrm{SO}_{4}$ solution in the presence of different concentrations of CTMAB at $308 \mathrm{~K}$.

Table II shows that corrosion current density $\left(\mathrm{I}_{\text {corr }}\right)$ decreases with increasing the inhibition concentration. This decrease is more predominant at higher concentration, especially at $10^{-1} \mathrm{M}$. Decrease in corrosion rate could be due to simply blocking effect of adsorbed inhibitor. These molecules in the form of layer, act as a barrier. It is also observed from Table II that the Tafel's slope values $b_{a}$ and $b_{c}$ increase with increasing the concentration for all the temperatures. The increase in values of $b_{c}$ indicates that blocking of mild steel surface by inhibitor takes place due to suppression of hydrogen evolution. 


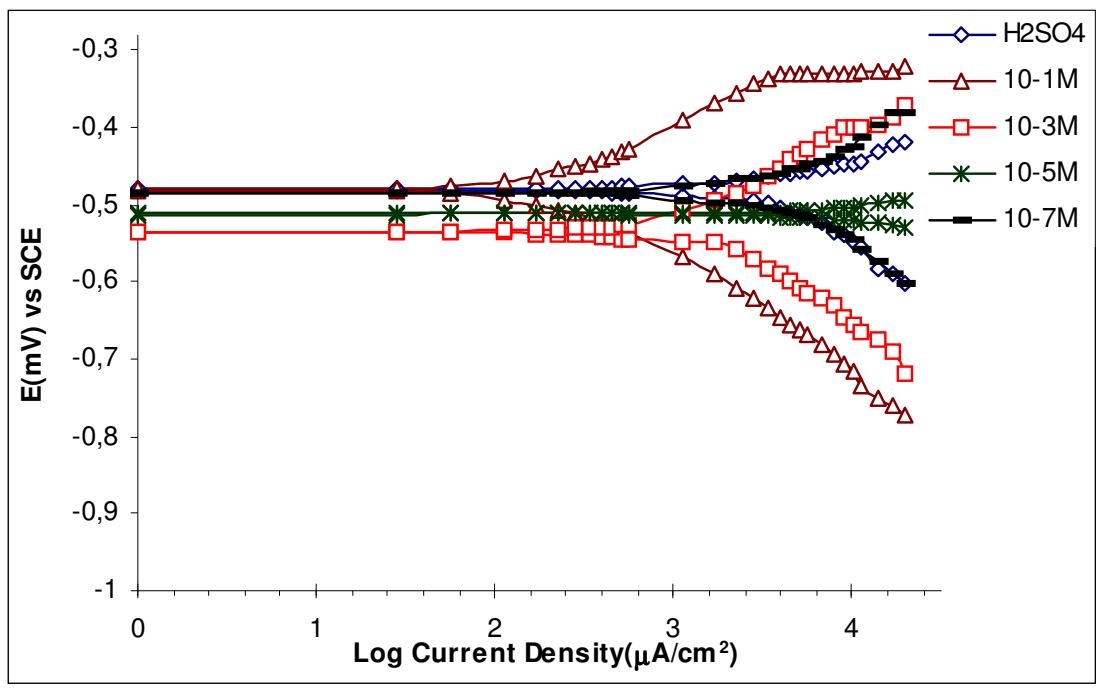

Figure 3. Galvanostatic polarization curves of mild steel in $1 \mathrm{~N}_{2} \mathrm{SO}_{4}$ solution in the presence of different concentrations of CTMAB at $318 \mathrm{~K}$.

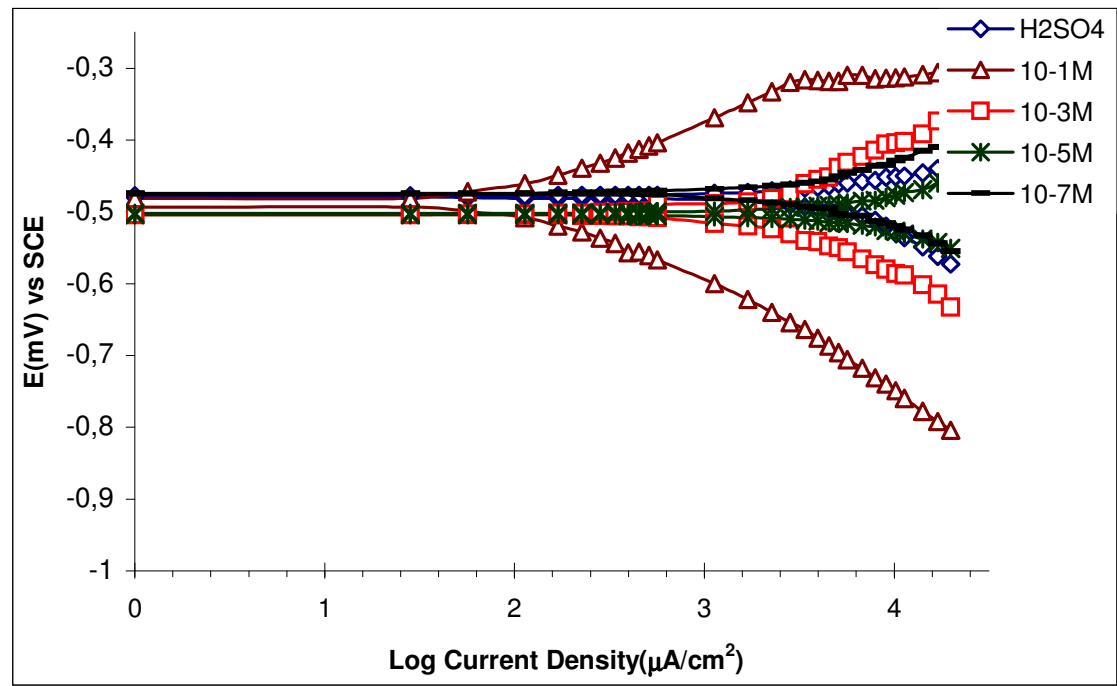

Figure 4. Galvanostatic polarization curves of mild steel in $1 \mathrm{~N}_{2} \mathrm{SO}_{4}$ solution in the presence of different concentrations of CTMAB at $328 \mathrm{~K}$.

The shift in the value of $\mathrm{E}_{\text {corr }}$ is not regular hence it shows that inhibitor is of mixed type. The corrosion inhibition efficiency (I\%) has been calculated by the following eq. (1).

Table II shows that corrosion inhibition increases with increase in concentration. It is because of surface coverage of mild steel inhibitor, but there is no gradual change of inhibition efficiency with rise in temperature from $298 \mathrm{~K}$ to $328 \mathrm{~K}$. The inhibition efficiency reaches about $96 \%$ with solution containing $10^{-1} \mathrm{M}$ inhibitor at $328 \mathrm{~K}$ temperature. This explains that CTMAB inhibitor adsorbs better at high concentration and causes more surface coverage and hence better inhibition. CTMAB has long chain of hydrocarbon, which is found good inhibition for mild steel and this long chain hydrocarbon surface-active agents are capable of forming micelles. 
Table II. Electrochemical parameters of mild steel in $1 \mathrm{~N} \mathrm{H}_{2} \mathrm{SO}_{4}$ in the presence of $\mathrm{N}$ cetyl N,N,N-trimethyl ammonium bromide (CTMAB) as additive.

\begin{tabular}{lcccccc}
\hline $\mathrm{T} / \mathrm{K}$ & $\begin{array}{c}\text { Solution } \\
\mathrm{mol} / \mathrm{L}^{-1}\end{array}$ & $\begin{array}{c}\mathrm{E}_{\text {corr }} \\
\mathrm{mV}\end{array}$ & $\begin{array}{c}\text { Log } \mathrm{i}_{\text {corr }} \\
\mu \mathrm{A} / \mathrm{cm}^{2}\end{array}$ & $\begin{array}{c}\mathrm{b}_{\mathrm{c}} \\
\mathrm{mV} / \mathrm{dec}\end{array}$ & $\begin{array}{c}\mathrm{b}_{\mathrm{a}} \\
\mathrm{mV} / \mathrm{dec}\end{array}$ & $\% \mathrm{I}$ \\
\hline 298 & 0 & 512 & 3.45 & 99 & 141 & - \\
& $10^{-7}$ & 503 & 3.16 & 48 & 39 & 48.71 \\
& $10^{-5}$ & 523 & 2.99 & 41 & 40 & 68.87 \\
& $10^{-3}$ & 509 & 2.55 & 144 & 214 & 87.41 \\
& $10^{-1}$ & 462 & 2.25 & 162 & 319 & 93.69 \\
\hline 308 & 0 & 522 & 3.38 & 111 & 151 & - \\
& $10^{-7}$ & 500 & 3.04 & 59 & 41 & 54.29 \\
& $10^{-5}$ & 511 & 2.96 & 38 & 72 & 61.98 \\
& $10^{-3}$ & 505 & 2.61 & 143 & 218 & 83.01 \\
& $10^{-1}$ & 421 & 2.20 & 79 & 162 & 93.39 \\
& 0 & 500 & 3.35 & 75 & 73 & - \\
\hline 328 & $10^{-7}$ & 480 & 3.25 & 47 & 72 & 20.56 \\
& $10^{-5}$ & 511 & 3.00 & 11 & 22 & 55.33 \\
& $10^{-3}$ & 521 & 2.41 & 120 & 112 & 88.51 \\
& $10^{-1}$ & 480 & 2.08 & 159 & 240 & 94.62 \\
\hline 0 & $10^{-7}$ & 480 & 3.29 & 41 & 93 & - \\
& $10^{-5}$ & 480 & 3.30 & 49 & 45 & 18.20 \\
& $10^{-3}$ & 506 & 2.96 & 30 & 24 & 53.22 \\
& $10^{-1}$ & 508 & 2.32 & 32 & 24 & 89.28 \\
& & 510 & 1.87 & 31 & 23 & 96.19
\end{tabular}

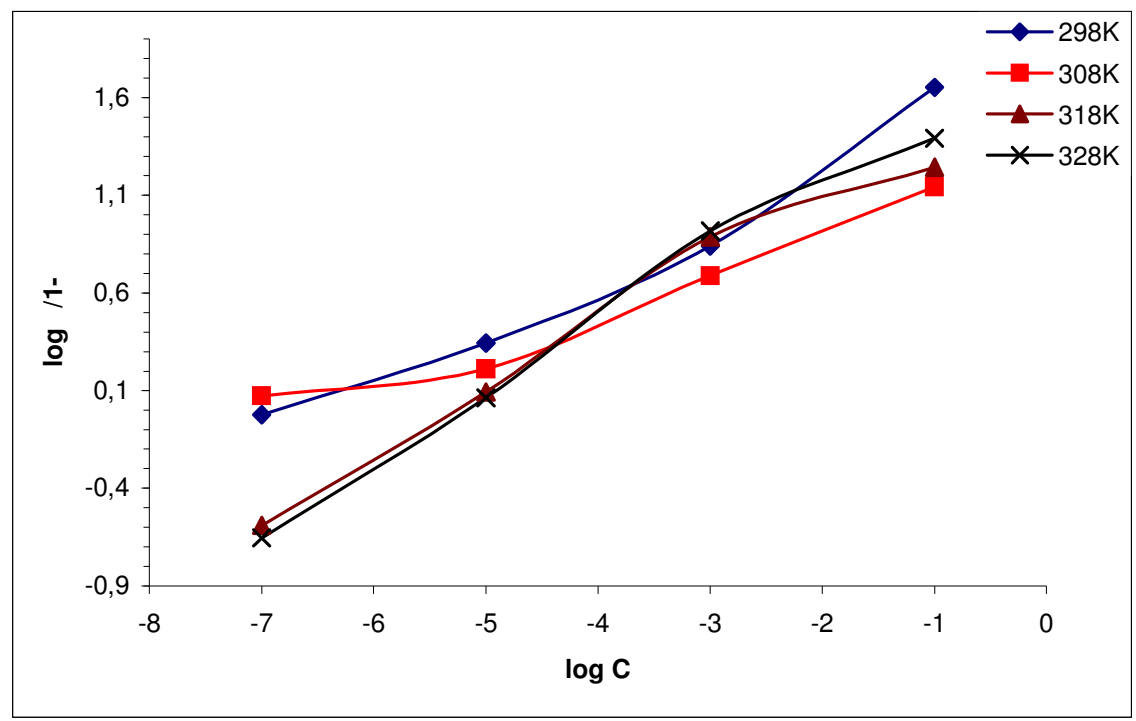

Figure 5. Variation of the surface coverage vs. concentration of CTMAB at different temperatures. 


\section{Adsorption kinetics}

With high concentration of inhibitor a protective inhibitor layer formed on the mild steel surface, which reduces the chemical attack of metal. The surface coverage $\theta$ values have been obtained from electrochemical measurements for various concentrations. There are many adsorption isotherms to study the adsorption process. Here Langmuir adsorption isotherm is tested. Fig. 5 shows the plot of $\log \theta / 1-\theta$ vs. $\log C$ graph, a straight line with approximately unit slope. The value of heat of adsorption can be calculated from the formula

$$
\log \frac{\theta}{1-\theta}=\log A+\log C-\frac{Q_{a d s}}{2.3 R T}
$$

where $\mathrm{A}$ is Arrhenius constant, $\mathrm{C}$ is inhibitor concentration and $\mathrm{Q}$ is heat of adsorption.

The value of heat of adsorption for CTMAB is $5.90 \mathrm{kcal} / \mathrm{mol}$.

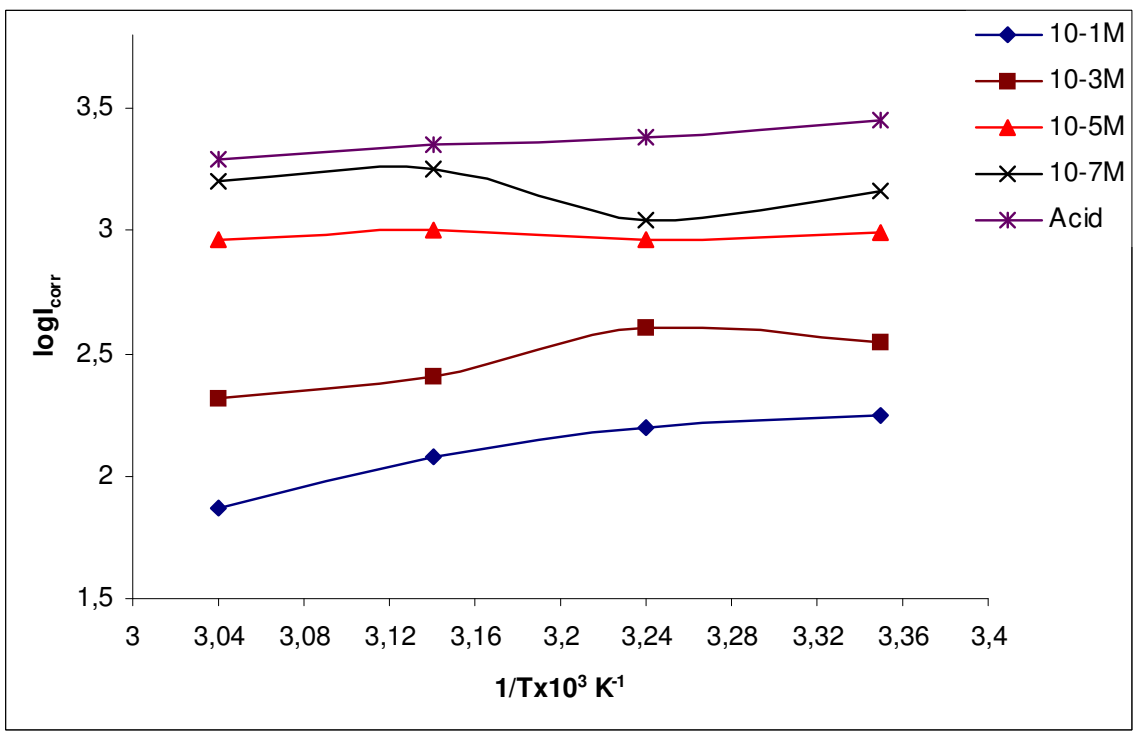

Figure 6. Variation of the corrosion current vs. reciprocal of temperature at different concentrations of CTMAB.

To calculate the activation energy, the current densities are plotted against temperature in absence and presence of inhibitor (Fig. 6). The value of activation energy can be found out by Arrhenius equation.

$$
\frac{\partial \log I_{c o r r}}{\partial \mathrm{T}}=\frac{\mathrm{E}_{a}}{R T^{2}}
$$

where $E_{a}$ is the activation energy. The value of activation energy of CTMAB is $66.74 \mathrm{kcal} / \mathrm{mol}$.

FTIR study of the inhibitor

To find out the types of bonding for organic molecule adsorbed on the surface of solid, FTIR study has been conducted. Silica gel has been chosen because of 
large surface area of adsorption of organic molecule and yields a spectrum of moderate intensity. The various peaks in spectra of pure and silica gel adsorbed additives are shown in Fig. 7 and 8 and there vibrational modes are reported in Table III.

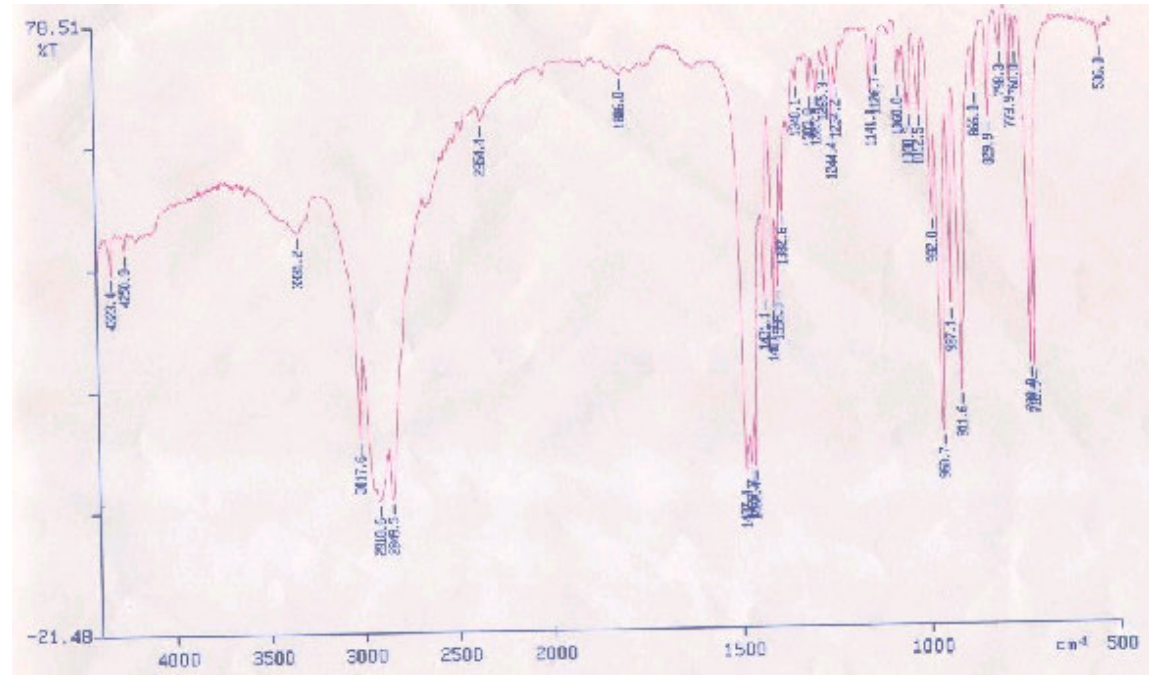

Figure 7. FTIR spectrum of pure CTMAB inhibitor.

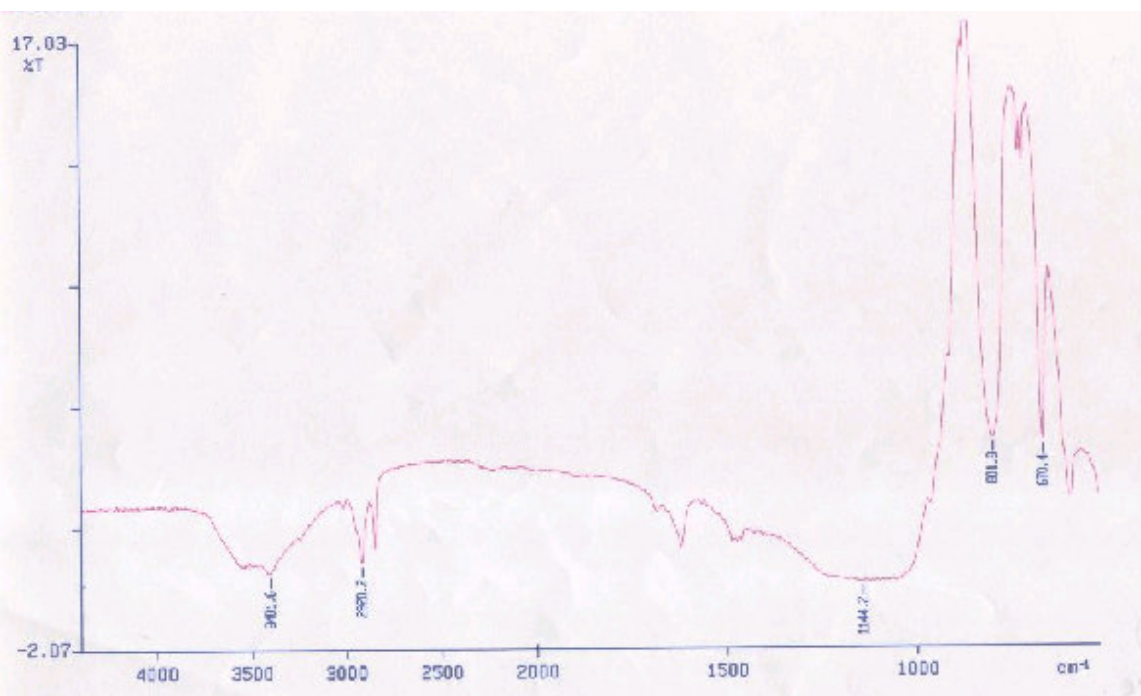

Figure 8. FTIR spectrum of CTMAB inhibitor adsorbed on silica gel.

The spectra of CTMAB indicate the disappearance of $\mathrm{N}-\mathrm{C}, \mathrm{N}-\mathrm{H},-\mathrm{CH}_{2}-$ and $\mathrm{N}$ $\mathrm{H}_{\text {wagg }}$ and merging of two peaks for $\mathrm{C}-\mathrm{H}_{\text {str }}$ bond into single peak. From the above observation it can be concluded that adsorption of this inhibitor over solid surface takes place through $\mathrm{N}-\mathrm{C}$ bond, $\mathrm{N}-\mathrm{H}$ bond and $\mathrm{N}-\mathrm{H}_{\text {wagg. }}$. 
Table III. Frequency values for FTIR adsorption peaks of pure and adsorbed inhibitor.

\begin{tabular}{|c|c|c|}
\hline CTMAB & CTMAB (adsorbed) & Peak \\
\hline 2918.6 & 2920.2 & C-H \\
\hline 1068.0 & - & N-C \\
\hline 1487.4 & - & $-\mathrm{CH}_{2}$ \\
\hline
\end{tabular}

\section{Scanning Electron Microscopic study}

To study the surface morphology of mild steel coupons SEM technique has been used. The surface features of mild steel specimen are examined after exposed to $1 \mathrm{~N} \mathrm{H}_{2} \mathrm{SO}_{4}$ solution in the absence and presence of the inhibitor at concentrations $10^{-7} \mathrm{M}$ and $10^{-1} \mathrm{M}$. Fig. 9, 10, 11 and 12 show the surface morphology of plain mild steel, in $1 \mathrm{~N} \mathrm{H}_{2} \mathrm{SO}_{4}$ and corroded surfaces after dipped in CTMAB inhibitor at $10^{-7} \mathrm{M}$ and $10^{-1} \mathrm{M}$. The micrograph obtained from different concentrations shows that the surfaces are inhibited due to the formation of protective film on mild steel surface in the presence of the inhibitor. Further, the protective film in the case of this compound has better protecting properties at higher concentrations.

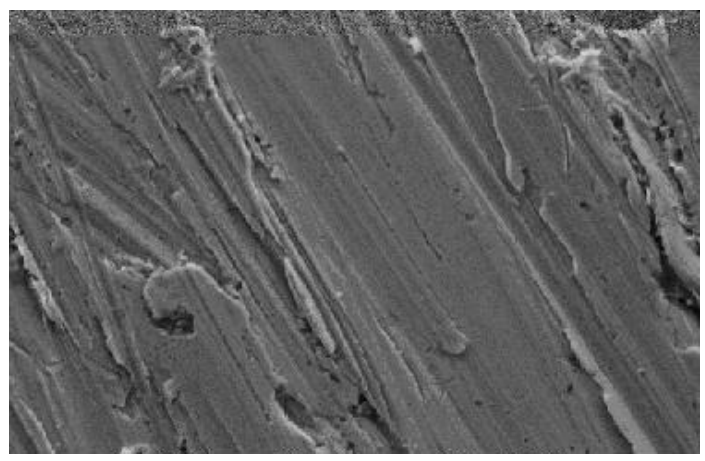

Figure 9. Scanning electron micrograph of plain mild steel at 2000 magnification.

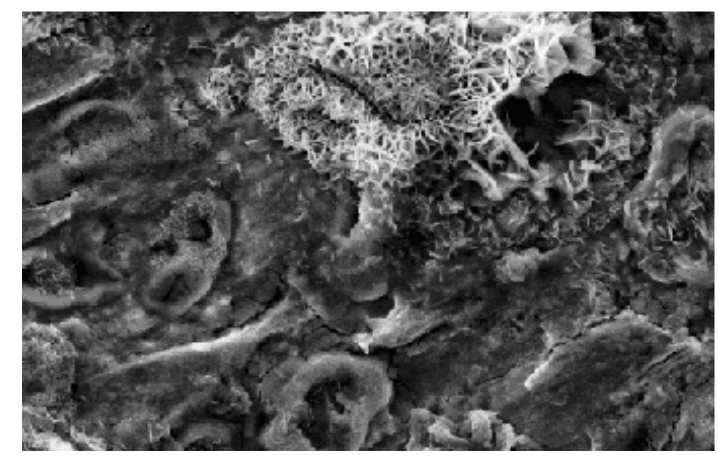

Figure 10. Scanning electron micrograph of mild steel in $\mathrm{H}_{2} \mathrm{SO}_{4}$ at 2000 magnification. 


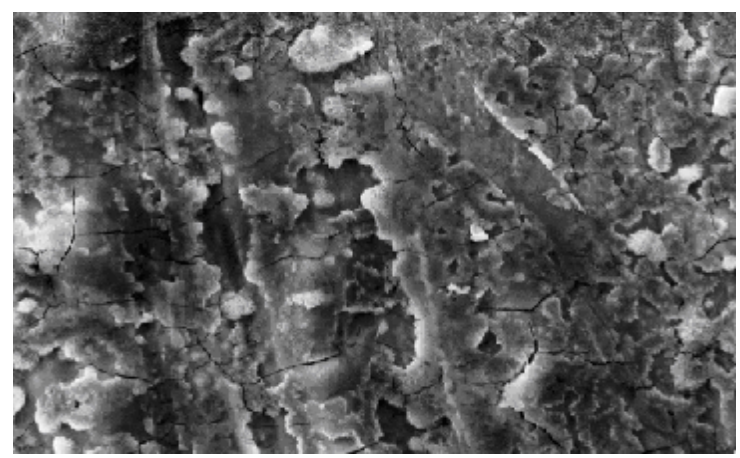

Figure 11. Scanning electron micrograph of mild steel in the presence of $10^{-7} \mathrm{M}$ CTMAB in $1 \mathrm{~N} \mathrm{H}_{2} \mathrm{SO}_{4}$ at 2000 magnification.

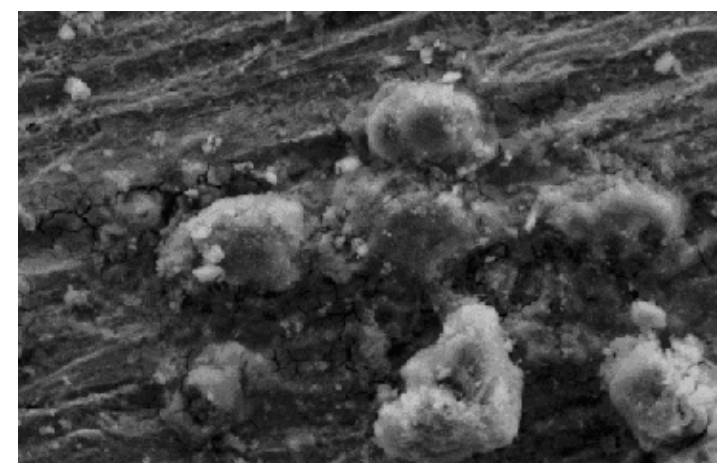

Figure 12. Scanning electron micrograph of mild steel in the presence of $10^{-1} \mathrm{M}$ CTMAB in $1 \mathrm{~N} \mathrm{H}_{2} \mathrm{SO}_{4}$ at 2000 magnification.

\section{Conclusions}

1. CTMAB acts as effective inhibitor in the acid environment.

2. The inhibition efficiency increases with the increase in CTMAB concentration.

3. The inhibition of mild steel in CTMAB is of mixed type.

4. The weight loss measurements are in good agreement with electrochemical method.

5. The adsorption of CTMAB on mild steel surface obeys Langmuir adsorptions isotherm.

6. The FTIR spectra show the adsorption nature.

7. The SEM analysis has shown that inhibition of corrosion by CTMAB is due to the formation of film on the steel surface.

\section{References}

1. L.D. Skryler, E.A. Streltsova and T.L. Skryleva, Protection Metals USSR 27-6 (1991) 193.

2. A. Swift, A.J. Paul and J.C. Vickerman, Surface Interface Analysis 20-1 (1993) 27. 
3. M. Studnicki, Hungarian J. Ind. Chem. 19-3 (1991) 193.

4. S.N. Raicheva, B.V. Aleksiev and E.I. Sokolova, Corros. Sci. 34-2 (1993) 343.

5. S.M. Beloglazov, Z.I. Dzhafarov, V.N. Polyakov and N.N. Demushia, Protection Metals USSR 27-6 (1991) 810.

6. S.L. Granese, B.M. Rosales, C. Oviedo and J.O. Zerbino, Corros. Sci. 33-9 (1992) 1439.

7. F. Zucchi, G. Trabanelli, and G. Brunoro, Corros. Sci. 33-7 (1992) 1135.

8. A.A. Fottah, E.M. Mabrouk, R.M.A. Elgalil ans M.M. Ghoneim, Bull. Soc. Chim. France 1 (1991) 48.

9. W.W. Frenier, Mater. Perf. 36-2 (1996) 63.

10. A. Frignani, M. Tassinari, L. Meszaros and G. Trabanelli, Corros. Sci. 32 (1991) 903.

11. B.B. Paty, Indian J. Tech. 29 (1991) 595.

12. B.V. Savithiri and S.M. Mayanna, Bull. Electrochem. 4 (1988) 875. 